\title{
Work-Life Balance among Teaching Hospital Nurses in Malaysia
}

\author{
Mohd Said Nurumal ${ }^{1}$, Sachiko Makabe ${ }^{2}$, Farah Ilyani Che Jamaludin ${ }^{1}$, Hairil Fahmi Mohd Yusof ${ }^{1}$, \\ Khin Thandar Aung ${ }^{1} \&$ Yanika Kowitlawakul ${ }^{3}$ \\ ${ }^{1}$ International Islamic University Malaysia, Malaysia \\ ${ }^{2}$ Akita University, Japan \\ ${ }^{3}$ National University of Singapore, Singapore \\ Correspondence: Mohd Said Nurumal, Department of Critical Care Nursing, Kulliyyah of Nursing, International \\ Islamic University Malaysia, PO Box 141, 25710 Kuantan, Pahang, Malaysia.
}

Received: February 27, 2017 Accepted: April 23, 2017 Online Published: July 10, 2017

doi:10.5539/gjhs.v9n9p81 URL: https://doi.org/10.5539/gjhs.v9n9p81

IRB Approval Number 313/20/4/10 - IREC351 - 20130319

\begin{abstract}
Extreme workload and poor working environment have a negative impact on the emotional and physical statuses among nurses. The study has contributed to evaluate work-life balance and its related factors among teaching hospital nurses. It was aimed to examine the work-life balance and its related factors among teaching hospital nurses. A cross-sectional study using a universal sampling technique was conducted. 1002 nurses were included from the Teaching hospital of Klang Valley, Malaysia. The instrument was adapted from NIOSH Generic Job Stress Questionnaire and QoL questionnaire from WHO, and it was used to measure the quality of work-life balance. Non-work activities, job requirement, supervisor support, job satisfaction, manageability, social and environmental variables have independently influenced work-life balance among nurses. Furthermore, quality of life variables has positively influenced the work-life balance $(\mathrm{P}<0.050)$. Work life balance and organizational commitment can have a positive relationship. Whereas, Nurses working in fixed shifts were observed with greater work-life balance as compared to the nurses working in multiple shifts. A friendly environment in the professional sector plays a major role for developing motivation and enthusiasm among workers.
\end{abstract}

Keywords: environment, nurses, teaching, workload, work-life balance, Malaysia

\section{Introduction}

Work-life balance is an idea that includes the prioritizing between the lifestyle and work along with balancing career and lifestyle together, which often seems a difficult goal in an individual's life. Working environment offered by an employer has a significant influence on the emotional health of the workers. The engagement of employees to promote programs has the substantial impact on the performance of employees (Anitha, 2014; Engel et al., 2014). Numerous researches have indicated that the employees would have a higher level of participation and motivation towards job matters, when their employers offer a good working environment (Engel et al., 2014; Timilsina Bhandari et al., 2015; Hinami et al., 2012). The staff ultimately relies on the management and their practices for job satisfaction (Buerhaus et al., 2015). Nevertheless, excessive workload and poor working environment affects greatly on psychological aspects due to ever-growing trends of the healthcare industry nowadays (Engel et al., 2014).

Buerhaus et al. (2015) has identified that excessive working hours within clinical settings for nurses can cause severe depression and imbalance hormones. As a result, the nurses tend to consume more food, smoke frequently and drink alcoholic beverages to eradicate fatigue, stress and sleepiness from their life (Antunes et al., 2010; Spiegel et al., 2009). Different studies have shown that nurses tend to make more errors during work like needle stick injuries and medication errors, which may also cause patient dissatisfaction (Stimpfel et al., 2012; Kunaviktikul et al., 2015; Trinkoff et al., 2011).

A study conducted by Sakthivel \& Jayakrishnan (Sakthivel \& Jayakrishnan, 2012) has indicated that the work-life balance among nurses is an important phenomenon because of providing healthcare to the patients. Focusing on the work-life balance as the main variable, it has been evaluated from the recent research that job satisfaction and work-life balance in the nursing profession are important factors for the delivery of quality healthcare among 
patients (Azeem \& Altalhi, 2015; Azeem \& Akhtar, 2014).

The study has the potential to contribute in the nursing practice along with evidence based practices by recognizing the crucial factors, leading to work-life imbalance, experienced by nurses in Malaysia. It has intended to identify the requirements to restructure the working conditions of the nurses, and to lessen schedule irregularity and work imbalance. These two aspects have been considered as the main factors that led to increase in stress and resulted in negative attitudes and poor psychological health.

\subsection{Aim of Study}

The general objective of the study is to examine work-life balance and its related factors among teaching hospital nurses. In addition, the specific objective is to identify factors of social demography, jobs nature, and quality of life towards work-life balance among nurses.

\section{Study Background}

The study has introduced a conceptual framework, which described the factors influencing the job satisfaction and work-life balance. A good place to work without stress, better satisfaction and motivation, reduced absenteeism, and lower turnover should be controlled by the hospital administration. The conceptual framework has proposed certain job related factors among nurses as shown in Figure 1.

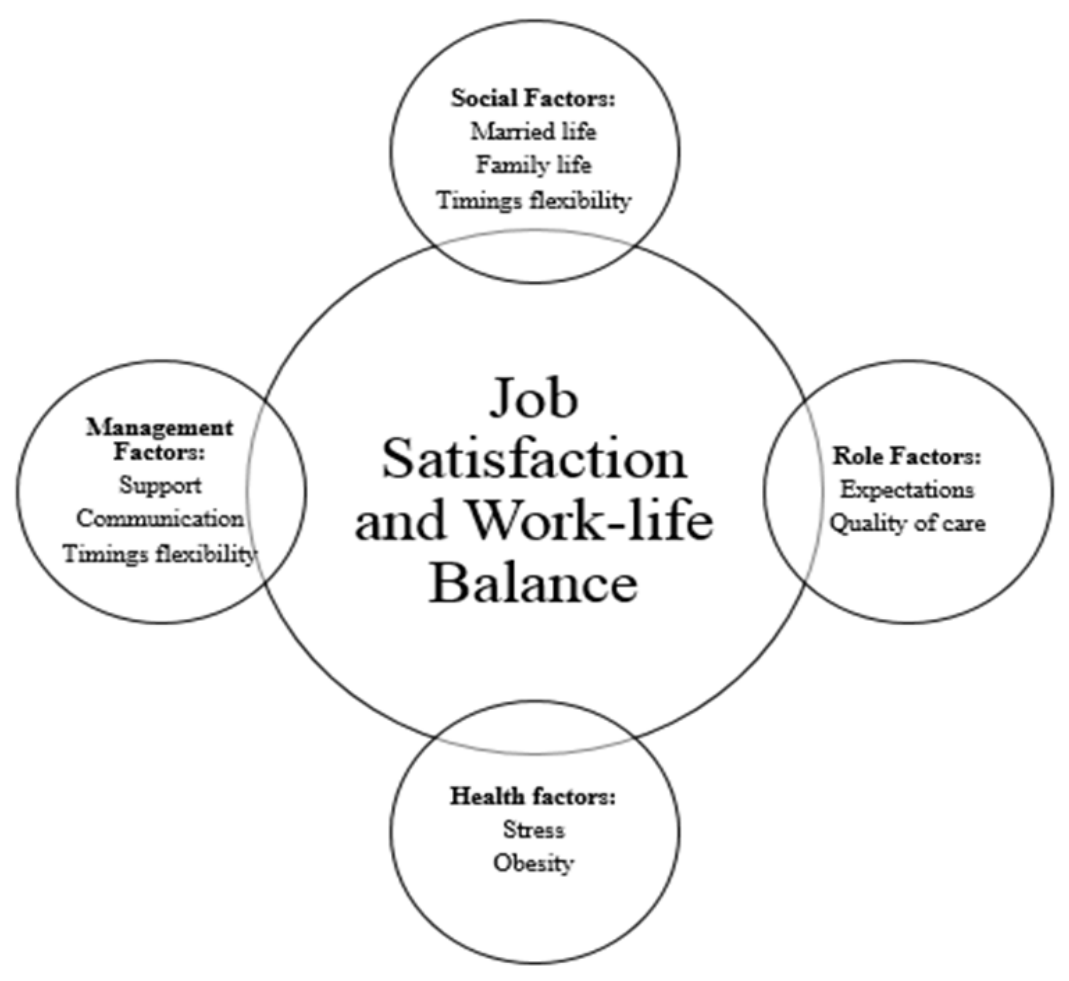

Figure 1. Conceptual framework of factors influencing nurses' intention to stay

\subsection{Social Factors}

Shu-Yu et al. (2014) mentioned that there is no relationship between the marital status and work-life balance. Even though the married population dominated the study, it did not present the factor for influencing work-life balance. It is further evaluated that the irregular sleeping pattern of nurses might affect the personal role in the family; consequently, having inadequate time spending for their family (Spiegel et al., 2009; Stimpfel et al., 2012; Kunaviktikul et al., 2015). Moreover, long working hours have affected energy level after work, so nurses seemed to have difficulty in compensating time with their family (Almalki et al., 2012).

HA1: Quality of Life is significantly influenced from the physical, psychological, social and environmental factors among nurses.

\subsection{Health Factors}

An epidemiological study showed an association between long working hours and obesity. Nurses, who work 
under pressure and long working hours, tend to compensate their stressful work-life, sleepiness, and fatigue by consuming more foods and alcoholic drink (Antunes et al., 2010). By the time, nurses who practically used to have such kind of lifestyles would be obese and have chronic diseases like diabetic mellitus and hypertension (Spiegel et al., 2009). A study by Stimpfel et al. (2012) has examined the information from different states of nurses, their patients, and hospitals. It has been reported that shifts greater than thirteen hours were interconnected to the dissatisfaction of patients. Particularly, patients observed that nurses were not interacting well and they were unable to provide help, whenever they needed. The results showed that nurses had greater risk of burnout, in case of working more than thirteen hours per day. Relatively, less sleep increases the chances for reduced job performance, obesity, and wide range of chronic diseases (Caruso, 2014). A review on shift works and obesity by Antunes et al. (2010) has concluded that there is a comparable epidemiological evidence for a relationship between obesity and shift work. Long working hours and obesity have been examined by few studies and concluded that there is a positive association between obesity and long working hours (Bannai \& Tamakoshi, 2014; Solovieva et al., 2013; Luckhaupt et al., 2014).

HA2: There is a positive association between chronic and mental diseases and long working hours among nurses.

\subsection{Role Factors}

Nurses, who have currently become a major group in the health care system, are reflected as a severe group and observed suffering from the poor quality of work-life balance. The stakeholders of healthcare have suggested that nurses' practitioners could help to mitigate the adverse impact of primary healthcare (Buerhaus et al., 2015). As a result, Malaysian nurses tend to migrate developed countries, which offer greater working environment, better career pathway, and better lifestyles (Timilsina Bhandari et al., 2015; Hinami et al., 2012; Buerhaus at al., 2015; Barnett et al., 2010).

HA3: Imbalance between the personal and organizational commitments will lead to some negative consequences among nurses.

\subsection{Management Factors}

Makabe et al. (2015) mentioned that work shift pattern resulted in inadequate period for nurses in getting enough rest between the shift. As the transition period between shifts is fast, it might distort the brain activity from wakefulness to sleep (Smith et al., 1999). Wilkins (2007) stated that sleep deprivation turned nurses to have low concentration level and cannot communicate in good manners with clients. This aspect might be one of the important causes which burn out syndrome between patients and nurses (Engel et al., 2014).

HA4: Work shift flexibility assist nurses to work and communicate with patients in good manners

\section{Methodology}

\subsection{Study Design and Participants}

The study opted a cross-sectional research design and involved 1002 respondents from University Malaya Medical Centre (UMMC), Petaling Jaya, Selangor. The survey was conducted in one of the teaching hospitals in Klang Valley. The survey questionnaires were distributed among 1002 nurses working in the hospital. The quantitative research design was opted to analyze the data through SPSS (Statistical Package of Social Sciences). Nurses, working in the UMMC, were included in the study regardless of their caste, religion, language, and other socio-demographic background. Both married and unmarried nurses were included; however, nurses, who have left working at UMMC, were excluded. Nurses from different educational background were also included. The study was commenced only among female employees and included hospital nurses of all positions ranging from lower rank to the top rank, who were working currently in hospitals. The data was collected from the nurses, who were not on leave and performing their duties in the hospitals at the time of data collection. The respondents, who understand Malay and English language and provided the consent to participate in the study, were included. Moreover, the boxes were kept safely and were impossible for the completed questionnaires to be visible or collected by others. After a month, the boxes were collected from the nursing offices for the analysis. Meanwhile, the data of each respondent was kept private and confidential.

The age of respondents was ranged from 20 to 59 years with the mean age 28.84 ( $\mathrm{SD}=8.86$ ). Regarding gender, majority of respondents were female (94.0\%); while, men were only $6.0 \%$. Respectively, the total number of 773 nurses $(77.1 \%)$ was from a diploma educational background. While, another 167 nurses $(16.7 \%)$ were from certificate level, and 62 nurses (6.2\%) were from degree and master educational background. Meanwhile, the total number of nurses per shift in average were $6.67(\mathrm{SD}=3.10)$. Additionally, an average total number of healthcare assistants were $3.26(\mathrm{SD}=3.28)$. In the day shift, the average time of the official break in minutes was $33.23(\mathrm{SD}=$ 
$18.04)$ and for the unofficial break was $14.53(\mathrm{SD}=10.58)$. In contrary, the average time of official breaks in night shift was $40.58(\mathrm{SD}=17.63)$ and for the unofficial break was $32.39(\mathrm{SD}=17.76)$. The percentage of annual leaves taken by the participants was $62.6 \%$.

Table 1. Association between socio demographic characteristics and work life balance $(\mathrm{N}=1002)$

\begin{tabular}{|c|c|c|c|c|}
\hline Socio Demographic & & & r-value & p-value \\
\hline Age & & & 0.02 & .470 \\
\hline \multirow[t]{2}{*}{ Experiences (months) } & & & 0.02 & .584 \\
\hline & Mean & SD & t-value & $\mathrm{p}$-value \\
\hline Gender & & & 1.52 & .130 \\
\hline Woman & 14.15 & 2.96 & & \\
\hline \multirow[t]{2}{*}{ Man } & 13.55 & 2.95 & & \\
\hline & & & F-stat (df) & $\mathrm{p}$-value \\
\hline Marital Status & & & $0.43(2)$ & .651 \\
\hline Married & 14.06 & 2.98 & & \\
\hline Single; Never Married & 14.14 & 2.85 & & \\
\hline Single; Divorced & 14.55 & 4.08 & & \\
\hline Religion & & & $0.76(2)$ & .516 \\
\hline Buddhism & 14.52 & 2.05 & & \\
\hline Others & 13.48 & 3.50 & & \\
\hline Muslim & 14.13 & 2.97 & & \\
\hline Hindu & 13.66 & 2.98 & & \\
\hline Educational Level & & & $1.72(2)$ & .180 \\
\hline Certificate & 14.49 & 3.03 & & \\
\hline Diploma & 14.02 & 2.97 & & \\
\hline Degree \& Master & 14.21 & 2.66 & & \\
\hline
\end{tabular}

\subsection{Measurement}

The questionnaire was adapted by NIOSH Generic Job Stress Questionnaire (Deguchi et al., 2016) and also composed with Sense of Coherence (SOC) questionnaires from the original author, Antonousky (Shu-Yu et al., 2014) and Quality of Life questionnaires from WHO (Smoth et al., 1999). 25 variables were established from the questionnaire and computed accordingly as in the previous version of study (Deguchi et al., 2016). The reliability test was examined in a pilot study involving 20 nurses, who did not participated in the main study. The Cronbach's Alpha was 0.97, which exceeded requirement value of 0.70 (Deguchi et al., 2016).

\subsection{Procedure}

Universal sampling approach has been applied in the study. Firstly, the objectives and potential benefits of the study have been focused through permission letter and the proposal was sent to the Director of Clinical Research Centre (CRC) of UMMC. Nurse Managers in each unit distributed the questionnaire to the nurses, according to the inclusion criteria. The respondents were allowed to complete the survey within a month. However, duration time for filling in the assessment was only 20-30 minutes.

\subsection{Data Analysis}

Raw data from the questionnaire was entered into the Statistical Package of Social Science (SPSS) version 20. The level of significance chosen for all analysis was $\mathrm{P}<.05$. Multiple Linear Regression tests were applied to model the relationship between variables of interest. While, one way ANOVA test was applied to determine the association between job nature and work-life balance. Afterwards, Pearson Correlation test was used to determine a relationship between continuous data. Age, experiences, number of nurses and assistant nurses, break hour, overtime hours, annual leaves, control scale, non-work activities, job requirement, social support, mental demand, doctor-nurse relationship, job satisfaction were obtained. Balance of work and private life, sense of coherence and 
quality of life towards work-life balance have also been assessed.

\section{Results}

The relationship between socio-demographic characteristics and work-life balance has been presented. However, none of the characteristics have shown significant value $(p$-value $=.050)$ to relate with work-life balance. For instance, marital status did not show any significant value $(\mathrm{P}<.050)$. It was similar to educational level as the $\mathrm{P}$-value was .180, which exceeded the maximum $\mathrm{p}$-value as shown in table 1.

The fixed shift showed a significant association towards work-life balance $(\mathrm{p}$-value $=.038)$. Nurses, who were working in fixed shift, have greater work-life balance score (mean=14.33, $\mathrm{SD}=2.69)$ as compared to nurses that are not working in fixed shift (mean=13.94, $\mathrm{SD}=2.82$ ). Moreover, there was a significant relationship between annual leaves and work-life balance ( $\mathrm{p}$-value $=.018, \mathrm{r}$-value $=0.08$ ). All of the four sub-categories showed a significant relationship into work-life balance with task control ( $\mathrm{p}$-value $<.001, \mathrm{r}$-value $=-0.17$ ), decision control ( $\mathrm{p}$-value $<.001$, $\mathrm{r}$-value $=-0.14)$, physical environment control $(\mathrm{p}$-value $<.001, \mathrm{r}$-value $=-0.12)$, and resource control (p-value $<.001$, r-value $=-0.13$ ). Furthermore, non-work activities of nurses presented a significant relationship with work-life balance ( $p$-value $=.002, r$-value $=-0.10$ ). Job requirement has also been observed with significant relationship regarding work-life balance $(\mathrm{p}$-value $<.001, \mathrm{r}$-value $=-0.19)$ as shown in Table 2 .

The Quality of life (QoL) has been assessed in four variables, including physical, psychological, social and environmental. All the four variables were significantly related to work-life balance where $(\mathrm{P}<.050)$. There is a significant linear relationship between non-work activities and WLB $(p<.001)$. There is a significant linear relationship between job requirements and WLB $(\mathrm{p}<.001)$. Those with scores of 10 in WLB will have 1 less square in job requirements. There is a significant linear relationship between supervisor support and WLB $(\mathrm{p}<.001)$. There is a significant linear relationship between management and WLB $(p<.001)$. Nurses who have the higher level of manageability of their work will have higher levels of WLB. There is a significant linear relationship between social life and WLB ( $<<.001)$. There is a significant linear relationship between environmental support and WLB $(\mathrm{p}<.001)$. Nurses who claimed to have good environmental support were observed with highest score of their WLB. With 7 significant variables, the model explained $25.0 \%$ of the variation of the WLB in the study sample. $(\mathrm{R} 2=0.25)$ as shown in Table 3.

Table 2. Association between Job Nature and Work-life Balance $(\mathrm{N}=1002)$

\begin{tabular}{|c|c|c|c|c|}
\hline & & & F-stat (df) & p-value \\
\hline Nurse Manager & 13.78 & 2.69 & & \\
\hline Senior Staff Nurse & 14.12 & 3.04 & & \\
\hline Staff Nurse & 14.13 & 2.97 & & \\
\hline Work shift & & & $.45(2)$ & .637 \\
\hline Rotating Shift & 14.13 & 2.98 & & \\
\hline Permanent Shift & 14.05 & 2.86 & & \\
\hline Office Hour & 13.65 & 2.71 & & \\
\hline Unit Type & & & $2.01(2)$ & .134 \\
\hline OPD & 14.27 & 3.06 & & \\
\hline Ward & 13.92 & 2.93 & & \\
\hline \multirow[t]{2}{*}{ ICU/OR/Cardiac } & 13.80 & 2.24 & & \\
\hline & & & r-value & $\mathrm{p}$-value \\
\hline Number of Beds & & & -0.04 & .176 \\
\hline Total Registered Nurses & & & -0.07 & $.034^{*}$ \\
\hline Total Assistant Nurse & & & -0.04 & .160 \\
\hline \multicolumn{5}{|l|}{ Break during working hour } \\
\hline Official Day Break & & & 0.07 & $.030^{*}$ \\
\hline Official Night Break & & & 0.02 & .573 \\
\hline Unofficial Day Break & & & 0.02 & .573 \\
\hline
\end{tabular}

* Other variables are mentioned in the detailed table 
Table 3. Multivariable Analysis of Respondents ( $\mathrm{N}=1002)$

\begin{tabular}{|c|c|c|c|c|c|c|}
\hline Quality Of Life & \multicolumn{2}{|c|}{ R-value } & & \multicolumn{3}{|l|}{ p-value } \\
\hline Physical & \multicolumn{2}{|l|}{0.15} & & \multicolumn{3}{|l|}{$<.001 *$} \\
\hline Psychological & \multicolumn{2}{|l|}{0.08} & & \multicolumn{3}{|l|}{$.013^{*}$} \\
\hline Social & \multicolumn{2}{|l|}{0.15} & & \multicolumn{3}{|l|}{$<.001^{*}$} \\
\hline Environment & \multicolumn{2}{|l|}{0.21} & & \multicolumn{3}{|l|}{$<.001^{*}$} \\
\hline \multirow{3}{*}{ Variables } & \multicolumn{4}{|c|}{ MLR (Multiple Linear Regression) } & & \\
\hline & \multirow{2}{*}{ Adj. B } & \multicolumn{2}{|c|}{$95.0 \% \mathrm{CI}$} & & \multirow{2}{*}{ t-stat. } & \multirow{2}{*}{ p-value } \\
\hline & & Lower & Upper & & & \\
\hline Fixed Shift & 0.29 & -0.04 & 0.63 & & 1.74 & .082 \\
\hline Total Registered Nurses & -0.001 & -0.04 & 0.02 & & -0.48 & .631 \\
\hline Official Day Break & 0.001 & -0.005 & 0.01 & & 0.83 & .404 \\
\hline Annual Leaves & 0.001 & -0.003 & 0.01 & & 1.08 & .281 \\
\hline Task Control & -0.241 & -0.68 & 0.20 & & -1.07 & .284 \\
\hline Decision Control & -0.23 & -0.63 & 0.18 & & -1.10 & .268 \\
\hline $\begin{array}{l}\text { Physical Environment } \\
\text { Control }\end{array}$ & -0.17 & -0.51 & 0.18 & & -0.95 & .343 \\
\hline Resource Control & -0.15 & -0.51 & 0.21 & & -0.81 & .416 \\
\hline Non-work Activities & -0.20 & -0.30 & -0.09 & & -3.52 & $<.001 *$ \\
\hline Job Requirement & -0.12 & -0.18 & -0.06 & & -3.86 & $<.001 *$ \\
\hline
\end{tabular}

*Other variables have been discussed in the detailed tables

The analysis was based on multiple regressions, which has predicted the work-life-balance in the form of equation: Work-life balance $=13.78-(0.20 \times$ Non-work activities $)-(0.12 \times$ Job requirements $)-(0.09 \times$ Supervisor support $)$ $+(1.78 \times$ Job satisfaction $)+(0.14 \times$ Manageability $)+(0.01 \times$ Social variable in $\mathrm{QoL})+(0.02 \times$ Environmental variable in $\mathrm{QoL})$. It is understandable that any imbalance between the personal and organizational commitments along with inefficiency in managing the priorities of life would lead to some serious consequences in every variable. The outcomes would result in the form of reduced job satisfaction, poor productivity and performance, low level of commitment towards the organization, increase in absenteeism and an ultimate intention to leave the organization. Thus, the work-life balance and the perception of the employee well-being have been recognized as an essential element for the success and growth of both; the employee and the organization. Work shift flexibility assist nurses to work and communicate with patients in good manners, so hypothesis 4 has been accepted.

\section{Discussion}

The present study has focused on the work-life balance among teaching hospital nurses in Malaysia. The factors related to the work-life imbalance among nurses have been evaluated, which may assist the healthcare management to decrease the workload among the nurses. The above conducted tests for analysis have suggested that there is a need to carefully monitor the level of all factors regarding work place, demographic, motivation, stress and other benefits to enhance the quality of life among nurses. This practice is expected to provide satisfaction in the personal life of nurses.

Nurses, working in fixed shifts, were observed with greater work-life balance as compared to the nurses working in rotational shifts or multiple shifts. The results also supported the outcomes of past study, which observed that the fixed shift significantly affects work-life balance (Makabe et al., 2015). However, the results were not consistent, when defining the relationship between work shift patterns towards work-life balance. Meanwhile, there was a significant relationship between total registered nurse $(\mathrm{RN})$, break during working hour, and overtime hours towards work-life balance. Such finding was similar to previous studies, where all of these three variables were interrelated and significantly affected work-life balance among nurses (Kunaviktikul et al., 2015; Almalki et al., 2012; Smith et al., 1999). Shortage of nurses was identified as the main problem. Due to the shortage of staff, nurses are also given non-nursing tasks (Almalki et al., 2012). 
According to the present study, there is also a positive influence of annual leaves on work-life balance among nurses. Physical, psychological, social and environmental factors were observed to be significantly associated with the work-life balance. According to a study, a large number of nurses spent most of the time on work as compared to private life, so they have poor work life pattern (Makabe et al., 2015). Only 36.9\% of nurses from the population study can balance their working time and private life. Whereas, almost $63.1 \%$ of the nurses have poor work-life balance; thus, it increased the rate of turnover, poor job satisfaction, and ultimately poor Quality of Life (QoL) (Hinami et al., 2012). The present study can be compared with the previous study conducted by Makabe (Makabe et al., 2015) in Japan, where the prevalence of improper proportion between work life and private life among nurses was very poor. The maintenance and development of data source regarding the nurse's workforce would expand the chances of policy researchers to understand the clinical practices (Almalki et al., 2012).

Regarding control scale that assessed autonomous power, the result could be comparable to the previous findings. For certain extent, it causes job dissatisfaction and frustration among nurses. Other studies in Thailand also presented nurses as an individual, who have been given power and opportunity to acquire good spirit, more enthusiasm, less stress and more commitment in the task (Antunes et al., 2010; Spiegel et al., 2009; Stimpfel et al., 2012; Kunaviktikul et al. 2015; Trinkoff et al., 2011; Shu-Yu et al., 2014; Makabe at al., 2015; Smith et al., 1999; Deguchi et al., 2016).

Experiences and educational level play significant roles in determining association with the work-life balance, where it can affect nurses physically, psychologically and socially. Experience and high education of nurses have shown high order thinking skills in managing conflicts as compared to non-experienced and low educational level of nurses (Almalki et al., 2012; Haus \& Smolensky, 2006). Ministry of Health indicated that Malaysia would be in critical shortage of nurses in the year 2020, due to the massive loss of Malaysian nurses through migration to other countries (Barnett et al., 2010). Ironically, the nurses' ratio to population of Malaysia as required by the WHO, which is 1:200 (Chu \& Moy, 2015).

WHO has indicated that South American countries have a ratio of 1.25 nurses for every 1000 population. Southeast Asian countries mostly indicated ratios of below than 3.30 nurses for every 1000 population except Singapore, which is a developed country with 9.60 nurses for 1000 population (Kimman et al., 2012; Gaughan et al., 2013). Makabe et al. (2015) agreed that steps should be taken to solve problems of the workplace itself and create positive work-life balance to find solution for turnover among developing countries' nurses.

Social support was significant in determining association with the working environment. The study was related to previous studies, which showed a lack of supervisor guidance, poor peer support, and de-motivated family members were determinants in defining the level of job dissatisfaction (Buerhaus et al., 2015). Due to the challenging job of nurses, this group of people need accompany in dealing with the stress at work place and home. Nurses working in internal and external wards especially the married ones experiences greater stress (Chiang \& Chang, 2012).

Serious attention has been given to the concept of work-life balance by different organizations, researchers, and HR practitioners. The main reason for this attraction could be due to the increasing demand of work along with increased family demands. This study has attempted to identify the work-life balance in the nursing sector and to investigate the issues that are faced with their possible outcomes. Additionally, the study has also endeavored to identify new score and possible scope for further research with a notion to achieve better modeling and to ensure higher work-life balance and delivery of performance. In conclusion, non-work activities, job requirement, SV support, job satisfaction, manageability, social and environmental variables are significantly associated with work-life balance. Therefore, necessary measures should be taken to eradicate the issues that have affected personal life satisfaction and their work periodically.

This kind of research could be initiated among both private and government hospitals of several different common departments including the OP, ICU, Medical and Surgery; therefore, the research would be helpful to obtain a wider picture regarding work life balance among female nurses in different departments of hospital.

\section{Acknowledgment}

The author is very thankful to World Health Organization(WHO) for granted us to use their instrument and to all the associated personnel in any reference that contributed in/for the purpose of this research. Further, this research holds no conflict of interest and is partially funded by Akita University.

\section{Ethical Consideration}

The research got approval from the Kuliyyah of Nursing Research Committee, IIUM first, and then proceeded with International Islamic University Malaysia Research Committee (IREC). Moreover, the permission has also 
been obtained by IRB committee to conduct the study. Thus, after gaining the approval from IREC and IRB, the research had been sent to the University Malaya Medical Centre (UMMC) and finally approached to each nursing department and units in the hospital.

\section{Competing Interests Statement}

The authors declare that they have no competing or potential conflicts of interest.

\section{References}

Almalki, M. J., FitzGerald, G., \& Clark, M. (2012). Quality of work life among primary health care nurses in the Jazan region, Saudi Arabia: a cross-sectional study. Human resources for health, 10(1), 30.Doi: https://doi.org/10.1186/1478-4491-10-30

Anitha, J. (2014). Determinants of employee engagement and their impact on employee performance. International Journal of Productivity and Performance Management.Doi: https://doi.org/10.1108/IJPPM-01-2013-0008

Antunes, L. C., Levandovski, R., Dantas, G., Caumo, W., \& Hidalgo, M. P. (2010). Obesity and shift work: chronobiological aspects. Nutrition research reviews, 23(01), 155-168.Doi: https://doi.org/10.1017/S0954422410000016

Azeem, S. M., \& Akhtar, N. (2014). The Influence of Work Life Balance and Job Satisfaction on Organizational Commitment of Healthcare Employees. International Journal of Human Resource Studies, 4(2), 18. Doi: 10.5296/ijhrs.v4i2.5667

Azeem, S. M., \& Altalhi, H. (2015). Role of Perceived Work-life Balance and Job Satisfaction in Developing Organizational Commitment among Hospital Employees in Saudi Arabia. International Journal of Academic Research in Business and Social Sciences, 5(12), 185-197.

Bannai, A., \& Tamakoshi, A. (2014). The association between long working hours and health: a systematic review of epidemiological evidence. Scandinavian journal of work, environment \& health, 40(1), 5-18.

Barnett, T., Namasivayam, P., \& Narudin, D. A. A. (2010). A critical review of the nursing shortage in Malaysia. International nursing review, 57(1), 32-39.Doi: https://doi.org/10.1111/j.1466-7657.2009.00784.x

Buerhaus, P. I., DesRoches, C. M., Dittus, R., \& Donelan, K. (2015). Practice characteristics of primary care nurse practitioners and physicians. Nursing Outlook, 63(2), 144-153.Doi: https://doi.org/10.1016/j.outlook.2014.08.008

Caruso, C. C. (2014). Negative impacts of shiftwork and long work hours. Rehabilitation Nursing, 39(1), 16-25.

Chiang, Y. M., \& Chang, Y. (2012). Stress, depression, and intention to leave among nurses in different medical units: Implications for healthcare management/nursing practice. Health Policy, 108(2), 149-157.Doi: 10.1016/j.healthpol.2012.08.027.

Chu, A. H. Y., \& Moy, F. M. (2015). Reliability and validity of the Malay International Physical Activity Questionnaire (IPAQ-M) among a Malay population in Malaysia. Asia Pacific Journal of Public Health, 27(2), NP2381-NP2389. Doi: https://doi.org/10.1177/1010539512444120

Deguchi, Y., Iwasaki, S., Konishi, A., Ishimoto, H., Ogawa, K., Fukuda, Y., ... \& Inoue, K. (2016). The Usefulness of Assessing and Identifying Workers' Temperaments and Their Effects on Occupational Stress in the Workplace. PloS one, 11(5), e0156339.Doi: https://doi.org/10.1089/jwh.2014.4858.

Engel, C. C., Bray, R. M., Jaycox, L. H., Freed, M. C., Zatzick, D., Lane, M. E., ... \& Tanielian, T. (2014). Implementing collaborative primary care for depression and posttraumatic stress disorder: Design and sample for a randomized trial in the US military health system. Contemporary clinical trials, 39(2), 310-319. Doi: https://doi.org/10.1016/j.cct.2014.10.002 1551-7144.

Gaughan, A. E., Stevens, F. R., Linard, C., Jia, P., \& Tatem, A. J. (2013). High resolution population distribution maps for Southeast Asia in 2010 and 2015. PloS one, 8(2), e55882.Doi: https://doi.org/10.1371/journal.pone.0055882

Haus, E., \& Smolensky, M. (2006). Biological clocks and shift work: circadian dysregulation and potential long-term effects. Cancer causes \& control, 17(4), 489-500.Doi: https://doi.org/10.1007/s10552-005-9015-4

Hinami, K., Whelan, C. T., Wolosin, R. J., Miller, J. A., \& Wetterneck, T. B. (2012). Worklife and satisfaction of hospitalists: toward flourishing careers. Journal of general internal medicine, 27(1), 28-36.Doi: https://doi.org/10.1007/s11606-011-1780-z 
Kimman, M., Norman, R., Jan, S., Kingston, D., \& Woodward, M. (2012). The burden of cancer in member countries of the Association of Southeast Asian Nations (ASEAN). Asian Pacific journal of cancer prevention, 13(2), 411-420. Doi:https://doi.org/10.7314/APJCP.2012.13.2.411

Kunaviktikul, W., Wichaikhum, O., Nantsupawat, A., Nantsupawat, R., Chontawan, R., Klunklin, A., ... \& Akkadechanunt, T. (2015). Nurses' extended work hours: patient, nurse and organizational outcomes. International nursing review, 62(3), 386-393.Doi: https://doi.org/10.1111/inr.12195

Luckhaupt, S. E., Cohen, M. A., Li, J., \& Calvert, G. M. (2014). Prevalence of obesity among US workers and associations with occupational factors. American journal of preventive medicine, 46(3), 237-248.

Makabe, S., Takagai, J., Asanuma, Y., Ohtomo, K., \& Kimura, Y. (2015). Impact of work-life imbalance on job satisfaction and quality of life among hospital nurses in Japan. Industrial health, 2014-0141.

Sakthivel, D., \& Jayakrishnan, J. (2012). Work life balance and Organizational commitment for Nurses. Asian Journal of Business and Management Sciences, 2(5), 1-6.

Shu-Yu, T. A. I., Pei-Chen, L. I. N., Yao-Mei, C. H. E. N., Hsin-Chia, H. U. N. G., Chih-Hong, P. A. N., Shung-Mei, P. A. N., ... \& Ming-Tsang, W. U. (2014). Effects of marital status and shift work on family function among registered nurses. Industrial health, 52(4), 296-303. Doi: https://doi.org/10.2486/indhealth.2014-0009

Smith, C. S., Robie, C., Folkard, S., Barton, J., Macdonald, I., Smith, L., ... \& Costa, G. (1999). A process model of shiftwork and health. Journal of occupational health psychology, 4(3), 207.Doi: https://doi.org/10.1037/1076-8998.4.3.207

Solovieva, S., Lallukka, T., Virtanen, M., \& Viikari-Juntura, E. (2013). Psychosocial factors at work, long work hours, and obesity: a systematic review. Scandinavian journal of work, environment \& health, 241-258.

Spiegel, K., Tasali, E., Leproult, R., \& Van Cauter, E. (2009). Effects of poor and short sleep on glucose metabolism and obesity risk. Nature Reviews Endocrinology, 5(5), 253-261. Doi: https://doi.org/10.1038/nrendo.2009.23

Stimpfel, A. W., Sloane, D. M., \& Aiken, L. H. (2012). The longer the shifts for hospital nurses, the higher the levels of burnout and patient dissatisfaction. Health Affairs, 31(11), 2501-2509.Doi: https://doi.org/10.1377/hlthaff.2011.1377

Timilsina Bhandari, K. K., Xiao, L. D., \& Belan, I. (2015). Job satisfaction of overseas - qualified nurses working in Australian hospitals. International nursing review, 62(1), 64-74.Doi: https://doi.org/10.1111/inr.12146

Trinkoff, A. M., Johantgen, M., Storr, C. L., Gurses, A. P., Liang, Y., \& Han, K. (2011). Nurses' work schedule characteristics, nurse staffing, and patient mortality. Nursing research, 60(1), 1-8.Doi: https://doi.org/10.1097/NNR.0b013e3181fff15d

Wilkins, K. (2007). Work stress among health care providers. Health Reports, 18(4), 33.

\section{Copyrights}

Copyright for this article is retained by the author(s), with first publication rights granted to the journal.

This is an open-access article distributed under the terms and conditions of the Creative Commons Attribution license (http://creativecommons.org/licenses/by/4.0/). 